\title{
Xilanase e $\beta$-glucanase na digestibilidade aparente de nutrientes do triticale pela Tilápia-do-nilo
}

\author{
[Xylanase and beta-glucanase on nutrient aparent digestibility of triticale by Nile tilapia] \\ L. Tachibana ${ }^{1}$, L.G.Q. Pinto $^{2,3}$, G.S. Gonçalves ${ }^{4}$, L.E. Pezzato ${ }^{3}$ \\ ${ }^{1}$ APTA - Pólo Vale do Ribeira \\ Caixa Postal 122 \\ 11900-970 - Registro, SP \\ ${ }^{2}$ Universidade Nacional de Colômbia - Bogotá, Col \\ ${ }^{3}$ Faculdade de Medicina Veterinária e Zootecnia - UNESP - Botucatu, SP \\ ${ }^{4}$ APTA - Instituto de Pesca - São Paulo, SP
}

\begin{abstract}
RESUMO
Avaliou-se o efeito de diferentes níveis do composto enzimático Natugrain Blend L®, que contém endoxilanase e endo-beta-glucanase, sobre a digestibilidade dos nutrientes e a energia do triticale pela tilápiado-nilo. $\mathrm{O}$ método para a determinação da digestibilidade foi o indireto, utilizando-se o óxido de crômio III $(0,10 \%)$. O delineamento experimental foi inteiramente ao acaso, com cinco tratamentos e três repetições. O nível de substituição da dieta-referência foi $50,0 \%$ pelo triticale. Os tratamentos foram 0,0 ; 150,$0 ; 300,0 ; 450,0$ e 600,0 $\mathrm{mg} \mathrm{kg}^{-1}$ de Natugrain Blend L, que contém 800 unidades $\mathrm{g}^{-1}$ de endo-1,3(4)- $\beta$ glucanase (BGU) e 36.600 unidades $\mathrm{g}^{-1}$ de endo-1,4- $\beta$-xylanase (EXU). Os coeficientes de digestibilidade aparente foram: da matéria seca, 76,$42 ; 74,01 ; 83,39 ; 82,97$ e $78,34 \%$; da proteína bruta 88,$19 ; 88,39$; 90,$52 ; 92,05$ e $88,34 \%$, da energia bruta 75,$93 ; 71,31 ; 81,78 ; 80,27$ e $78,62 \%$, respectivamente, para os níveis de inclusão na dieta 0,$0 ; 150,0 ; 300,0 ; 450,0$ e $600,0 \mathrm{mg} \mathrm{kg}^{-1}$ de Natugrain Blend L.Os resultados demonstram que $300 \mathrm{mg} \mathrm{kg}^{-1}$ do complexo de enzimas foi suficiente para aumentar o coeficiente de digestibilidade aparente da matéria seca. O composto de enzimas pode ser utilizado para aumentar a eficiência de aproveitamento dos nutrientes do triticale.
\end{abstract}

Palavras-chave: peixe, Oreochromis niloticus, enzimas, Triticum turgisecale

\begin{abstract}
The effects of different levels of Natugrain Blend L® enzymatic compound on triticale nutrients and energy digestibility by Nile tilapia were evaluated. The digestibility was indirectly determined with chromic oxide III (0.10\%) as an external marker. The level of substitution by triticale in the reference diet was $50 \%$. The treatments were 0, 150,300, 450, and $600 \mathrm{~g} \mathrm{~kg}$ of Natugrain Blend L, which contains 800 units $g^{-1}$ of endo-1,3(4)- $\beta$-glucanase (BGU) and 36.600 units $g^{-1}$ of endo-1,4- $\beta$-xylanase (EXU). The apparent digestibility coefficients were: dry matter 76.42, 74.01, 83.39, 82.97, and 78.34\%; crude protein $88.19,88.39,90.52,92.05$, and 88.34\%; crude energy 75.93, 71.31, 81.78, 80.27, and 78.62\%, respectively to inclusion levels of 0.0, 150.0,300.0, 450.0, and 600.0mg kg $\mathrm{gg}^{-1}$ of Natugrain Blend L in diet. Results demonstrated that $300 \mathrm{mg} \mathrm{kg}^{-1}$ of enzymes were enough to increase the dry matter apparent digestibility coefficient and energy. The enzyme compound can be used to increase the efficiency of triticale feed utilization.
\end{abstract}

Keywords: fish, Oreochromis niloticus, enzymes, Triticum turgisecale

Recebido em 19 de novembro de 2009

Aceito em 31 de março de 2010

Email: leotachibana@apta.sp.gov.br 


\section{INTRODUÇÃO}

O triticale (Triticum turgisecale) é um cereal desenvolvido a partir da hibridação do trigo com o centeio. Possui, como principais características, maior teor proteico em relação ao milho e menor teor de fibras, no entanto herdou componentes antinutricionais dos cereais de origem como os polissacarídeos não amiláceos (PNA) (Conte et al., 2003).

Os PNA são geralmente encontrados nos cereais como: centeio, cevada, trigo, triticale, aveia, arroz e, ainda, em algumas leguminosas. São constituintes da parede celular dos alimentos de origem vegetal e não podem ser digeridos pelos peixes, pois são resistentes à hidrólise enzimática no trato gastrintestinal. A incapacidade de digerir tais compostos reduz a energia digestível e prejudica, ainda, a absorção de outros nutrientes (Conte et al., 2003). Os PNA são representados pela pectina, celulose, lignina, arabinoxilanas (pentoses) e $\beta$-glucanos. As frações solúveis dos $\beta$-glucanos e dos arabinoxilanas nos cereais são consideradas como de maior importância na interferência da capacidade de utilização dos nutrientes da dieta (Classen, 1996). Os efeitos desses PNA são: aumento da viscosidade do quimo no intestino, proteção do alimento contra os ataques de enzimas digestivas, diminuição da digestibilidade da gordura pela inativação dos sais biliares e aumento na secreção pancreática de enzimas (Classen, 1996).

A utilização de enzimas microbianas na alimentação animal é a forma mais eficiente para aumentar o aproveitamento do carboidrato dos cereais que contém antinutricionais (Classen, 1996). As enzimas xilanase e glucanase são produzidas a partir dos microrganismos do gênero Aspergillus (Products..., 2003).

O nível de hidrólise necessária para aumentar o valor nutricional dos cereais é importante para determinar o tipo e a quantidade da enzima a ser utilizada (Classen, 1996). A viscosidade e/ou a encapsulação são os maiores efeitos do $\beta$ glucano e das arabinoxilanas, e apenas uma pequena fenda na molécula pesada do substrato é necessária para a enzima exógena aumentar a disponibilidade dos nutrientes (White et al., 1983; Campbell et al., 1986, citado por Classen, 1996).
$\mathrm{Na}$ nutrição animal, a utilização de enzimas digestivas exógenas tem mostrado bons resultados para o aumento da eficiência de utilização dos nutrientes. Em aves de corte, a utilização da xilanase $(0,10 \%$ - aproximadamente 4.000 Unidade de Endo-Xilanase - EXU) na dieta melhorou a conversão alimentar $(1,56$ para $1,47)$ quando as aves receberam dieta contendo $15,0 \%$ de farelo de arroz (Conte et al., 2003). Em suínos, os coeficientes de digestibilidade da matéria seca e do nitrogênio foram aumentados quando se incluiu 0,1\% (4.000 Unidades de Endo-Xilanase $\mathrm{g}^{-1}$ - EXU) de xilanase, derivada de Trichoderma longibrachiatum, em ração contendo cevada, trigo e centeio, alimentos com grande quantidade de PNA (Dersjant-Li et al., 2001). Ainda, em suínos, Hauschild et al. (2008) obsevaram aumento na proteína digestível da ração quando se adicionou o complexo enzimático (xylanase e beta-glucanase).

Alguns autores não obtiveram êxito com a utilização das enzimas exógenas, principalmente quando se avaliaram animais adultos, que possuem grande capacidade para digerir fibra dietética. Em suínos, Diebold et al. (2005) não observaram efeito positivo da inclusão de xilanase em dietas contendo, aproximadamente, $60 \%$ de trigo, e Högberg e Lindenberg (2004), ao trabalharem com ração contendo alto e baixo nível de PNA, oriundo principalmente do triticale, com e sem enzimas (endo-xilanase + beta-glucanase), verificaram aumento da proporção molar de ácido lático no íleo e diminuição de ácido acético em suínos, indicando mudança de dominância de bactérias do trato gastrintestinal.

A avaliação das enzimas digestivas em peixes é necessária para aumentar a eficiência de utilização dos nutrientes, reduzir o impacto ambiental e o custo de produção. O objetivo deste trabalho foi avaliar o coeficiente de digestibilidade aparente dos nutrientes e da energia do triticale com a inclusão das enzimas endo-1,3(4)- $\beta$-glucanase e endo-1,4- $\beta$-xylanase na forma do produto comercial Natugrain Blend L® (Basf - Ludwigshafen, Ger) em diferentes níveis.

\section{MATERIAL E MÉTODOS}

O experimento foi realizado na Faculdade de Medicina Veterinária e Zootecnia, Departamento 
de Melhoramento e Nutrição, Laboratório de Nutrição de Organismos Aquáticos - Aquanutri, unidade integrada ao Centro de Aquicultura da UNESP.

Cento e vinte tilápias, média de peso de $112,00 \pm 22,00 \mathrm{~g}$, foram alojadas em gaiolas de formato circular $(80,0 \mathrm{~cm}$ de diâmetro e $60,0 \mathrm{~cm}$ de altura), confeccionadas em tela plástica (malha de $1,5 \mathrm{~cm}$ entre-nós) instaladas em 10 aquários circulares de alimentação com formato cilíndrico e capacidade para 250L. Foram utilizados cinco aquários para coleta de fezes com fundo cônico, para favorecer a decantação das fezes, que eram coletadas no fundo do áquario em recipiente de $300 \mathrm{~mL}$. Tanto os aquários de alimentação quanto os de coleta de fezes eram ligados a um sistema de recirculação contínua de água, com filtro físico, biológico e temperatura controlada a $27,0 \pm 0,5^{\circ} \mathrm{C}$.

Os peixes foram inicialmente alimentados durante cinco dias com as dietas a serem testadas, para aclimatação. Posteriormente, no período matutino, foram alimentados a cada duas horas. No período vespertino, a alimentação dos peixes que entrariam na coleta de fezes foi intensificada a cada hora. No final de cada tarde (18 horas), cinco gaiolas eram transferidas para os aquários de coleta de fezes, onde permaneceram até a manhã do dia seguinte, quando, então, eram devolvidas ao respectivo aquário de alimentação. Somente após 24 horas os peixes seriam utilizados para nova coleta de fezes, em alternância com os peixes das outras cinco gaiolas.

As fezes de cada aquário de coleta foram secas em estufa a $55,0^{\circ} \mathrm{C}$, moídas em micro-moinho e conservadas a $-20,0^{\circ} \mathrm{C}$. Coletaram-se pelo menos $5 \mathrm{~g}$ de fezes (matéria seca) por repetição, usandose dois grupos de peixes em intervalo de 24 horas. Esse manejo, em que os peixes se alimentam em um sistema independente do utilizado para a coleta de fezes, evita a contaminação do material colhido com sua respectiva ração, conforme metodologia proposta por Pezzato et al. (2002). O processo de limpeza de todo o sistema, 15 minutos após a última refeição, permitiu preparar os aquários para uma nova coleta (dia seguinte)

A inclusão do triticale na dieta-referência (Tab. 1) foi de 50\%, e utilizou-se como marcador externo $0,1 \%$ de óxido de crômio III. O composto de enzimas, Natugrain Blend L, na forma líquida, foi pesado em balança analítica de precisão de quatro casas, para fornecer a concentração exata da enzima, diluído em $500 \mathrm{~mL}$ de água e adicionado e misturado à ração. A dieta foi processada em peletizadora experimental e seca em estufa com ventilação forçada a $55^{\circ} \mathrm{C}$ durante $24 \mathrm{~h}$.

Tabela 1. Composição percentual das dietas-referência e teste

\begin{tabular}{lcccccc}
\hline \multirow{2}{*}{ Alimento } & Dieta- & \multicolumn{5}{c}{ Natugrain Blend $\left.\mathrm{L}^{-1} \mathrm{~kg}^{-1}\right)$} \\
\cline { 3 - 6 } & referência & 0,0 & 150,0 & 300,0 & 450,0 & 600,0 \\
\hline Triticale & - & 50,0 & 50,00 & 50,0 & 50,0 & 50,0 \\
Albumina & 32,00 & 16,00 & 16,00 & 16,00 & 16,00 & 16,00 \\
Gelatina & 7,70 & 3,85 & 3,85 & 3,85 & 3,85 & 3,85 \\
Amido de milho & 44,58 & 22,24 & 22,23 & 22,22 & 22,20 & 22,19 \\
a -celulose & 6,00 & 3,00 & 3,00 & 3,00 & 3,00 & 3,00 \\
Antioxidante (BHT) & 0,02 & 0,01 & 0,01 & 0,01 & 0,01 & 0,01 \\
Óleo de soja & 6,00 & 3,00 & 3,00 & 3,00 & 3,00 & 3,00 \\
Fosfato bicálcico & 3,00 & 1,50 & 1,50 & 1,50 & 1,50 & 1,50 \\
NaCl & 0,10 & 0,05 & 0,05 & 0,05 & 0,05 & 0,05 \\
Supl. min. e vit. ${ }^{1}$ & 0,50 & 0,25 & 0,25 & 0,25 & 0,25 & 0,25 \\
Óxido de crômio III & 0,10 & 0,10 & 0,10 & 0,10 & 0,10 & 0,10 \\
\hline
\end{tabular}

'Quantidade por kg de suplemento: vitA 1200000UI; vitD ${ }_{3}$ 200000UI; vitE 12000mg; vitK ${ }_{3} 2400 \mathrm{mg}$; vitB ${ }_{1} 4800 \mathrm{mg}$; vitB $4800 \mathrm{mg}$; vitB $648000 \mathrm{mg} ; \mathrm{B}_{12} 4800 \mathrm{mg}$; ác. fólico $1200 \mathrm{mg}$; ác. pantotênico $12000 \mathrm{mg}$; vitC 48mg; biotina 48mg; colina 65mg; niacina 24000mg; Fe 10000mg; Cu 600mg; Mn 4000mg; Zn 6000mg; I 20mg; Co 2mg e Se $20 \mathrm{mg}$. 
Os tratamentos utilizados foram $0,150,300,450$ e $600 \mathrm{mg} \mathrm{kg}^{-1}$ de Natugrain Blend L, que continha 800 unidades $\mathrm{g}^{-1}$ de endo-1,3(4)- $\beta$-glucanase (BGU) e 36.600 unidades $\mathrm{g}^{-1}$ de endo-1,4- $\beta$ xylanase (EXU). A unidade BGU é definida como a atividade necessária para liberar 0,258 micromol de açúcar reduzido (equivalente em glicose) por minuto, em solução que contém $0,5 \%$ de $\beta$-glucano, $\mathrm{pH} 3,5$ e temperatura de $40^{\circ} \mathrm{C}$, e a EXU definida como a atividade necessária para liberar 1,00 micromol de açúcar reduzido (medido como equivalente em xilose) por minuto, em solução que contém $0,5 \%$ de arabinoxilanas, $\mathrm{pH} 3,5$ e temperatura de $40^{\circ} \mathrm{C}$ (Products..., 2003).

As análises realizadas nas dietas e nas fezes foram: matéria seca, proteína bruta, óxido de crômio e energia bruta para calcular os coeficientes de digestibilidade aparente. As análises para determinação da concentração de crômio nas fezes e nas rações foram realizadas a partir da mineralização ácida das amostras em blocos digestores (nítrico-perclórica) e posterior quantificação do crômio por espectrofotometria de absorção e coloração por difenilcarbazida (Graner, 1972). As análises quimicobromatológicas das rações e das fezes foram realizadas no Laboratório de Bromatologia do Departamento de Melhoramento e Nutrição Animal da FMVZ. A proteína bruta (PB) foi analisada pelo método de Kjeldhal (Nx6,25), a matéria seca (MS) o foi em estufa a $105^{\circ} \mathrm{C}$ durante 24h segundo AOAC (Official..., 1984) e a energia bruta (EB) com bomba calorimétrica (Parr Inst. Co. - Moline, Ill, EUA).

Os coeficientes de digestibilidade aparente (CDA) da MS, PB, EB das rações foram calculados com base no teor de $\mathrm{Cr}_{2} \mathrm{O}_{3}$ da ração e das fezes, segundo o método de determinação do CDA, conforme a fórmula (Austreng, 1978):

$\mathrm{Da}_{(\mathrm{n})}=100-\left[100\left(\frac{\% \mathrm{Cr}_{2} \mathrm{O}_{3 \mathrm{r}}}{\% \mathrm{Cr}_{2} \mathrm{O}_{3 \mathrm{f}}}\right) \times\left(\frac{\% \mathrm{~N}_{\mathrm{f}}}{\% \mathrm{~N}_{\mathrm{r}}}\right)\right]$, em que

$\mathrm{Da}_{(\mathrm{n})}=$ digestibilidade aparente do nutriente; $\mathrm{Cr}_{2} \mathrm{O}_{3 \mathrm{r}}=\%$ de óxido de crômio na ração; $\mathrm{Cr}_{2} \mathrm{O}_{3 \mathrm{f}}$ $=\%$ de óxido de crômio nas fezes; $\mathrm{N}_{\mathrm{r}}=$ nutrientes na ração; $\mathrm{N}_{\mathrm{f}}=$ nutriente nas fezes.

O CDA dos nutrientes e da energia do triticale foram calculados de acordo com a equação, proposta por Kleiber (1961), modificada por Forster (1999):
$C D A N_{\text {ing. }}=\frac{\left[(a+b) \times C D A N_{\text {teste }}-a \times C D A N_{\text {ref }}\right]}{b}$,

em que

$\mathrm{CDAN}_{\text {ing. }}=$ coeficiente de digestibilidade aparente do nutriente no ingrediente; $\mathrm{CDAN}_{\text {teste }}=$ coeficiente de digestibilidade aparente do nutriente da dieta-teste; $\mathrm{CDAN}_{\text {refer. }}=$ coeficiente de digestibilidade aparente do nutriente da dietareferência; $a=$ contribuição de nutrientes da dieta referência ao conteúdo de nutrientes da dieta-teste; $b=$ contribuição de nutrientes do ingrediente-teste ao conteúdo de nutrientes da dieta-teste; $a+b=$ nível do nutriente da dietateste.

O delineamento experimental foi o inteiramente ao acaso, com cinco tratamentos (níveis de Natugrain Blend L) e três repetições. Os dados foram submetidos a análises de variância e, posteriormente, ao teste Tukey, utilizando-se o programa estatístico SAS.

\section{RESULTADOS E DISCUSSÃO}

Os valores da composição químicobromatológica do triticale foram: matéria seca $=$ $87,71 \%$; proteína bruta $=12,71 \%$ e energia bruta $=3.900 \mathrm{kcal} \mathrm{kg}^{-1}$, valores próximos aos encontrados na literatura (Hughes, 1990; De Brum et al., 2000; Furlan et al., 2004), e tornam o triticale um bom substitituto do milho, pois possui concentração maior de proteínas na composição.

Os CDA do triticale avaliados com ração purificada contendo diferentes níveis do composto de enzimas Natugrain Blend L são apresentados na Tab. 2. Houve diferenças $(\mathrm{P}<0,05)$ entre os tratamentos quanto aos CDA da MS e EB

O CDA da MS foi mais alto $(\mathrm{P}<0,05)$ com a inclusão de 300 e $450 \mathrm{mg} \mathrm{kg}^{-1}$ em relação ao CDA dos tratamentos com 0 e $150 \mathrm{mg} \mathrm{kg}^{-1}$ de inclusão, e nenhum diferiu do tratamento com $600 \mathrm{mg} \mathrm{kg}^{-1}$. O CDA da MS $(76,42 \%)$ sem a adição da enzima foi mais elevado que o encontrado por Fontaínhas-Fernandez et al. (1999), Boscolo et al. (2002) e Tachibana (2007), respectivamente, 70,00; 68,51; 70,98\%. Esses autores utilizaram $30 \%$ de inclusão do alimento teste enquanto, neste trabalho, foram utilizados 
50\%. Esperava-se maior efeito antinutricional dos PNA com a maior inclusão do produto e, por consequência, maior efeito das enzimas adicionadas. O CDA da MS do alimento, no entanto, foi maior com a adição de maior quantidade de triticale na dieta-referência. Provavelmente, a análise de digestibilidade sofreu interferências do cultivar testado, do tamanho dos peixes e das instalações utilizadas, entre outros fatores.

O fornecimento individual dos alimentos-teste, para avaliação do CDA dos alimentos, seria o ideal, no entanto isto é dificultado por problemas de palatabilidade do alimento, capacidade de formação do pélete e pelo fato de a maioria dos alimentos não possuir todos os nutrientes exigidos pelo animal (Buerau et al., 2008). A metodologia desenvolvida por Cho e Slinger (1979), de utilizar-se do alimento-teste + dietareferência, geralmente resolve esses problemas. Mas a digestibilidade desse alimento sempre sofrerá interferência da dieta-referência (Buerau et al., 2008). Dependendo da quantidade de alimento-teste na dieta-referência, a digestibilidade pode ser afetada, como demonstrado por Hauschild et al. (2008), em suínos.

A inclusão de $300 \mathrm{mg} \mathrm{kg}^{-1}$ de Natugrain Blend L demonstrou ser suficiente para a melhora do CDA da MS do triticale, devido ao poder de hidrólise dos PNA (arabinoxilanas e $\beta$-glucanos) e ao seu aproveitamento como fonte energética. Níveis acima de $300 \mathrm{mg} \mathrm{kg}^{-1}$ do produto não proporcionaram aumento nos CDA da MS, portanto a utilização de maior quantidade do composto não é necessária para esse parâmetro.
Dersjant-Li et al. (2001) observaram, para suínos, aumento do CDA da MS com a inclusão de 4.000 unidades de xilanase $\mathrm{kg}^{-1}$. Neste trabalho, os resultados indicaram que 10.980 unidades de xilanase $\mathrm{kg}^{-1}$ resultaram em maior CDA da MS pela tilápia-do-nilo, portanto, as enzimas incluídas na dieta interferiram na digestibilidade dos alimentos. A quantidade de triticale incluída no alimento-teste, provavelmente, foi determinante para o maior efeito do composto enzimático, pois quanto mais substrato maior o efeito da enzima.

Trabalhos anteriores demonstram que a inclusão de $25,72 \%$ de triticale para o piavuçu, Leporinus macrocephalus (Nagae et al., 2001) ou de $30,30 \%$ para tilápia-do-nilo (Tachibana, 2007) não resultou em menor ganho em peso e nem pior conversão alimentar, e que foi importante a inclusão de maior quantidade do alimento-teste nas rações de digestibilidade para os antinutricionais do triticale demonstrarem o efeito da inclusão das enzimas. Camiruaga et al. (2001), ao trabalharem com ração contendo triticale $(0,33 \%$ de beta-glucanos e $3,91 \%$ de arabinoxilanas) e adicionando beta-glucanase, para frangos de corte, observaram aumento do peso vivo aos 21 dias e redução na conversão alimentar. Signor (2008) observou melhor conversão alimentar em tilápia-do-nilo alimentada com complexo enzimático, composto por amilase, protease, celulase, lipase, pectinase, xilanase, $\beta$-glucanase e fitase, o que foi confirmado com os resultados obtidos neste trabalho, pois a melhora na conversão alimentar está relacionada ao aumento da digestibilidade do alimento.

Tabela 2. Valores médios dos coeficientes de digestibilidade aparente (CDA) do triticale com diferentes níveis de inclusção de Natugrain Blend L (Endo-1,3(4)- $\beta$-glucanase + Endo-1,4- $\beta$-xilanase)

\begin{tabular}{lccccc}
\hline \multirow{2}{*}{ CDA (\%) } & \multicolumn{5}{c}{ Níveis de inclusão do Natugrain Blend L $\left(\mathrm{mg} \mathrm{kg}^{-1}\right)$} \\
\cline { 2 - 6 } & 0 & 150 & 300 & 450 & 600 \\
\hline Matéria seca & $76,42 \mathrm{ab}$ & $74,01 \mathrm{~b}$ & $83,39 \mathrm{a}$ & $82,97 \mathrm{a}$ & $78,34 \mathrm{ab}$ \\
& $( \pm 4,89)$ & $( \pm 3,16)$ & $( \pm 0,48)$ & $( \pm 0,66)$ & $( \pm 3,48)$ \\
Proteína bruta & 88,19 & 88,39 & 90,52 & 92,05 & 88,34 \\
& $( \pm 2,58)$ & $( \pm 2,46)$ & $( \pm 0,69)$ & $( \pm 0,72)$ & $( \pm 2,18)$ \\
Energia bruta & $75,93 \mathrm{ab}$ & $71,31 \mathrm{~b}$ & $81,78 \mathrm{a}$ & $80,27 \mathrm{ab}$ & $78,62 \mathrm{ab}$ \\
& $( \pm 5,41)$ & $( \pm 3,70)$ & $( \pm 0,29)$ & $( \pm 0,87)$ & $( \pm 3,42)$ \\
\hline
\end{tabular}

Letras diferentes na linha indicam diferenças entre os valores $(\mathrm{P}<0,05)$ pelo teste Tukey. 
Os CDA da PB não apresentaram diferenças estatísticas entre tratamentos ( $\mathrm{P}>0,05)$. Utilizando-se o índice relativo de comparações (IRC), pode-se observar que a inclusão de $450 \mathrm{mg}$ $\mathrm{kg}^{-1}$ determinou $4,19 \%$ a mais no CDA da PB que a não inclusão de enzimas, sugerindo que a adição do composto enzimático melhorou o CDA da PB, pois os PNA presentes no triticale dificultam a atuação das enzimas proteolíticas no bolo alimentar e a absorção da proteínaaminoácidos pelos intestinos, e que a hidrólise desses compostos liberam os componentes proteicos e energéticos para serem absorvidos pelos intestinos (Högberg e Lindberg, 2004).

O CDA da PB da ração sem a adição da enzima foi mais alto que o observado por FontaínhasFernandez et al. (1999) (79,60\%), mais baixo que o citado por Boscolo et al. (2002) (94,78\%) e próximo ao determinado por Tachibana (2007) $(87,33 \%)$. Os valores observados situam-se dentro dos padrões de digestibilidade encontrados na literatura especializada. Estas diferenças podem ser ocasionadas pela metodologia de coleta, análises químicas, quantidade de alimento-teste adicionado, entre outros (Halver e Hardy, 2002).

As enzimas utilizadas agem nos carboidratos, portanto melhores resultados ocorrem no CDA da MS, mas, também, no CDA da PB. Dänicke et al. (1999) observaram aumento da porcentagem de utilização do nitrogênio de 61,7 para $69,6 \%$ em frangos de corte ao utilizarem 2.552 EXU, em dieta contendo $56 \%$ de centeio, demonstrando que existe efeito da utilização das enzimas no CDA da proteína quando se utilizam grãos que contêm os PNA. Neste trabalho, houve tendência de melhores valores do CDA da PB com a adição das enzimas na dieta.

Hauschild et al. (2008) observaram que a digestibilidade da PB de rações que continham ou não enzimas exógenas (xilanase e $\beta$ glucanase) dependia diretamente da porcentagem de substrato (triticale - PNA) presente na dieta. Esses autores utilizaram 0, 30 e $60 \%$ de inclusão de triticale para avaliar a porcentagem de proteína digestível em suínos e determinaram que, sem a adição da enzima e o aumento da inclusão do triticale, a proteína digestível diminuía. Com a enzima, o aumento de triticale de 0 para $30 \%$ aumentou a proteína digestível e manteve-se semelhante com $60 \%$ de inclusão.
Neste trabalho, utilizaram-se $50 \%$, o que não foi suficiente, para expressar os efeitos dos PNA e das enzimas exógenas sobre a digestibilidade da $\mathrm{PB}$ do alimento pelos peixes.

Houve diferença $(\mathrm{P}<0,05)$ entre os tratamentos quanto ao CDA da EB. Sem a adição de enzimas, os valores do triticale foram menores que os encontrados por Boscolo et al.(2002) (80,55\%) e maiores que os verificados por FontaínhasFernandez et al. (1999) $(69,6 \%)$ e Tachibana (2007) (70,98\%), demonstrando que valores próximos são encontrados na literatura.

O tratamento com $300 \mathrm{mg} \mathrm{kg}^{-1}$ resultou em CDA da EB maior que o tratamento com $150 \mathrm{mg} \mathrm{kg}^{-1}$, e os tratamentos com 0,450 e $600 \mathrm{mg} \mathrm{kg}^{-1}$ não diferiram dos demais tratamentos. A não diferença observada entre o tratamento-controle e os demais tratamentos, provavelmente, justifica-se pelo alto coeficiente de variação encontrado. Numericamente isto pode ter importância econômica, ou seja, a adição do composto enzimático mantém a tendência benéfica do uso das enzimas exógenas.

Ogunkoya et al. (2006) observaram pequenos, mas significativos, aumentos nos CDA da matéria seca, nitrogênio, fósforo e energia quando incluíram o composto enzimático (xilanase, beta-glucanase, amilase, protease e celulase) na alimentação da truta arco-íris (Ocorhynchus mykiss) em rações que continham farelo de soja. Neste trabalho, observou-se aumento de $5,85 \%$ de diferença no CDA entre os tratamentos que apresentaram diferença significativa, isto é, o aumento foi de 2.961,27 para $3.189 .42 \mathrm{kcal} \mathrm{kg}^{-1}$ na energia digestível do triticale. Na formulação de rações para peixe, o maior CDA do alimento pode ser decisivo para sua utilização.

No entanto, algumas pesquisas não apresentaram resultados semelhantes. Högberg e Lindberg (2004), ao estudarem duas formulações para suínos, alta e baixa quantidade de PNA, com e sem adição das enzimas xilanase e betaglucanase, e utilizarem triticale, aveia, cevada, farelo de trigo e trigo como fontes de PNA, não observaram efeito da adição das enzimas no CDA da EB e nem na viscosidade do quimo no íleo. Possivelmente, a concentração das enzimas exógenas na ração não foi suficiente para demonstrar o efeito benéfico no CDA da EB, 
pois neste trabalho atingiu-se o melhor resultado numérico com $300 \mathrm{mg} \mathrm{kg}^{-1}$, e, também, o autor cita que suínos adultos têm maior capacidade de digerir PNA pela interação com as bactérias intestinais.

A utilização de $300 \mathrm{mg} \mathrm{kg}^{-1}$ do composto foi eficiente em aumentar o coeficiente de digestibilidade da matéria seca, proteína bruta e energia pela tilápia-do-nilo do triticale. O composto enzimático, que aumenta a digestibilidade do alimento, provoca também redução do impacto ambiental, pois todo composto não absorvido pelo animal é eliminado na forma de fezes no meio ambiente.

\section{CONCLUSÕES}

O composto de enzimas Natugrain Blend L® pode ser utilizado para aumentar a disponibilidade de nutrientes em rações para a tilápia-do-nilo que contenham os beta glucanos e as arabinoxilanas.

\section{REFERÊNCIAS BIBLIOGRÁFICAS}

AUSTRENG, E. Digestibility determination in fish using chromic oxide marking and analysis of contents from different segments of the gastrointestinal tract. Aquaculture, v.13, p.265$272,1978$.

BOSCOLO, W. R.; HAYASHI, C.; MEURER, F. Digestibilidade aparente da energia e nutrientes de alimentos convencionais e alternativos para a tilápia-do-nilo (Oreochromis niloticus, L.). Rev. Bras. Zootec., v.31, p.539545,2002

BUREAU, D.P.; KAUASHIK, J.K.; CHO, C.Y. Bioenergetics. In: HALVER, J.E.; HARDY, R.W. (Eds.). Fish nutrition. New York: Academic, 2008. p.1-59.

CAMIRUAGA M.; GARCIA, F.; ELERA, R., SIMONETTI, C. Respuesta productiva de pollos a la adición de enzimas exógenas a dietas basadas en maíz o triticale. Cienc. Invest. Agr., v.28, p.23-36, 2001.

CHO, C.Y., SLINGER, S.J. Apparent digestibility measurement in feedstuffs for rainbow trout. In: HALVER, J.E.; TIEWS, K. (Eds). Finfish nutrition and fishfeed technology. Berlin: Heenemann, 1979. v.II, p.239-247.
CLASSEN, H.L.Cereal grain starch and exogenous enzymes in poultry diets. Anim. Feed Sci. Technol., v.62, p.21-27, 1996.

CONTE, A.J.; TEIXEIRA, A.S.; FIALHO, E.T. et al. Efeito da fitase e xilanase sobre o desempenho e as características ósseas de frangos de corte alimentados com dietas contendo farelo de arroz. Rev. Bras. Zootec., v.32, p.1147-1156, 2003.

DÄNICKE, S.; FRANKE, E.; STROBEL, E. et al. Effect of vary dietary fat type and xylanase supplementation in rye containing diets on energy metabolism in male broilers. J. Anim. Physiol. Anim. Nutr., v.81, p.90-102, 1999.

DE BRUM, P.A.R.; ZANOTTO, D.L.; GUIDONI, A.L. et al. Triticale em dietas para frangos de corte. Pesq. Agropec. Bras., v.35, p.229-239, 2000.

DERSJANT-LI, Y.; SCHULZE, H.; SCHRAMA, J.W. et al. Feed intake, growth, digestibility of dry matter and nitrogen in young pigs as affected by dietary cation-anion difference and supplementation of xylanase. J. Anim. Physiol. Anim. Nutr., v.85, p.101-109, 2001.

DIEBOLD, G.; MOSENTHIN, R.; SAUER, W.C. et al. Supplementation of xylanase and phospholipase to wheat based diets for weaner pigs. J. Anim. Physiol. Anim. Nutr., v.89, p.316$325,2005$.

FONTAÍNHAS-FERNANDEZ, A.; GOMES, E.; REIS-HENRIQUES, M.A. et al. Replacement of fish meal by plant proteins in the diet of Nile tilapia: digestibility and growth performance. Aquac. Int., v.7, p.57-67, 1999.

FORSTER, I. A note on the method of calculating digestibility coefficients of nutrients provided by single ingredients to feeds of aquatic animals. Aquac. Nutr., v.5, p.143-145, 1999.

FURLAN, A.C.; MONTEIRO, R.T.; SCAPINELLO, C. et al. Avaliação nutricional do triticale extrusado ou não para coelhos em crescimento. Acta Scient., v.26, p.49-55, 2004.

GRANER, C.A.F. Determinação do crômio pelo método colorimétrico da S-difenilcarbazida. 1972. 112f. Tese (Doutorado) - Faculdade de Ciências Médicas e Biológicas, Universidade do Estado de São Paulo, Botucatu, SP. 
HALVER, J.; HARDY, R. Fish Nutrition. 3.ed. San Diego: Elsevier, 2002. 824p.

HAUSCHILD, L.; LOVATTO, P.A.; LEHNEN, C.R. et al. Utilização do triticale e de enzimas em dietas para suínos: digestibilidade e metabolismo. Arq. Bras. Med. Vet. Zootec., v.60, p.470-476, 2008.

HÖGBERG, A.; LINDBERG, J.E. Influence of cereal non-starch polysaccharides and enzymes supplementation on digestion site and gut environment in weaned piglets. An. Feed Sci. Techn., v.116, p.113-128, 2004.

HUGHES, S.G. Use of triticale as a replacement for wheat middlings in diets for Atlantic salmon. Aquaculture, v.90, p.173-178, 1990.

KLEIBER, M. The fire of life: An introduction to animal energetics. New York: Jonh Wiley \& Sons, 1961. p.255-257.

NAGAE, M.Y.; HAYASHI, C.; GALDIOLI, E. M. Inclusão do triticale em rações para alevinos de piavuçu, Leporinus macrocephalus (Garavello \& Britski, 1988) Acta Scient., v.23, p.849-853, 2001.

OFFICIAL methods of analysis. 12.ed. Washington, DC: AOAC, 1984. 1015p.

OGUNKOYA, A.E.; PAGE, G.I.; ADEWOLU, M.A. et al. Dietary incorporation of soybean meal and exogenous enzyme cocktail can affect physical characteristics of faecal material egested by rainbow trout (Oncorhynchus mykiss). Aquaculture, v.254, p.466-475, 2005.
PEZZATO, L.E.; MIRANDA, E.C.; BARROS, M.M. et al. Digestibilidade aparente de ingredientes pela tilápia-do-nilo (Oreochromis niloticus). Rev. Bras. Zootec., v.31, p.1595-1604, 2002.

PRODUCTS for the feed industry. Ludwgshafen: BASF, 2003 (Technical information). 158p.

SIGNOR, A.A. Processamento de rações $e$ utilização de complexo multienzimático na produção de juvenis de tilápia-do-nilo (Oreochromis niloticus). 2008. 49f. Dissertação (Mestrado) - Universidade do Oeste do Paraná, Marechal Cândido Rondon, PR.

TACHIBANA, L. Triticale na alimentação da tilápia-do-nilo. 2007. 61f. Tese (Doutorado) Faculdade de Ciências Agrárias e Veterinárias, Universidade Estadual Paulista, Jaboticabal, SP.

WHITE, W.B.; BIRD, H.R.; SUNDE, M.L. et al. Viscosity of $\beta$-D-glucan as a factor in the enzymatic improvement of barley. Poult. Sci., v.62, p.853-862, 1983. 